\title{
The quest to optimize neurodevelopmental outcomes in neonatal arch reconstruction: The perfusion techniques we use and why we believe in them
}

Richard G. Ohye, MD, ${ }^{a}$ Caren S. Goldberg, MD, MS, ${ }^{\mathrm{b}}$ Janet Donohue, MPH, MS, ${ }^{\mathrm{b}}$ Jennifer C. Hirsch, MD, MS, ${ }^{a}$

Michael Gaies, MD, ${ }^{\mathrm{b}}$ Marshall L. Jacobs, MD, ${ }^{\mathrm{c}}$ and James G. Gurney, PhD, ${ }^{\mathrm{b}}$ for the Michigan Congenital Heart Outcomes Research and Discovery Investigators

Major advances in surgical techniques and medical care have brought exciting change to the outcomes of children treated for complex congenital heart disease. Hypoplastic left heart syndrome, for example, was uniformly fatal only 30 years ago, but now has a 5-year survival of approximately $70 \% .^{1-4}$ Although the survival for those with surgically repaired complex congenital heart defects has markedly improved, associated morbidities remain high. The neurodevelopmental outcomes of infants and children requiring multiple cardiac operations in childhood are among the major concerns of those who care for patients with congenital heart disease.

Deep hypothermic circulatory arrest (DHCA), an adjunctive surgical technique that requires cooling the patient to $18^{\circ} \mathrm{C}$ and ceasing all blood flow to the entire body including the brain, has until recently been the standard intraoperative procedure used to perform aortic arch reconstruction in infants and young children. The development of DHCA in the early 1970s was a breakthrough that allowed for the operative treatment of many lesions previously not amenable to repair in neonates. Unfortunately, although still a mainstay in congenital heart surgery, DHCA is associated with the potential for poor neurodevelopmental outcomes. ${ }^{5-7}$

\section{ALTERNATIVE PERFUSION TECHNIQUES}

Regional cerebral perfusion (RCP), a recently described alternative to DHCA, involves directing blood flow to the central nervous system throughout aortic arch reconstruction. RCP, first described by Asou and colleagues ${ }^{8}$ in 1996 as an alternative to DHCA, is hypothesized to be potentially neuroprotective relative to DHC. Since 2000, multiple case series of patients managed with RCP have been published. ${ }^{9,10}$ In a piglet model, RCP was found superior to DHCA on neurobehavioral and histopathologic scores, al-

\footnotetext{
From the Departments of Surgery ${ }^{\mathrm{a}}$ and Pediatrics and Communicable Disease, ${ }^{\mathrm{b}}$ University of Michigan Medical School, Ann Arbor, Michigan; and Department of Cardiothoracic Surgery, Drexel University, ${ }^{c}$ College of Medicine, Philadelphia, Pennsylvania.

The Michigan Congenital Heart Outcomes Research and Discovery Program is supported by a grants from the Department of Surgery and the Department of Pediatrics and Communicable Disease, University of Michigan Medical School, Ann Arbor, Michigan.

Received for publication Oct 8, 2008; accepted for publication Oct 31, 2008.

Address for reprints: Richard G. Ohye, MD, 5144 CVC/SPC 5864, 1500 E. Medical

Center Drive, Ann Arbor, MI 48109-5864 (E-mail: ohye@umich.edu).

J Thorac Cardiovasc Surg 2009;137:803-6

$0022-5223 / \$ 36.00$

Copyright (c) 2009 by The American Association for Thoracic Surgery

doi:10.1016/j.jtcvs.2008.10.046
}

beit at a long period of DHCA (90 minutes). ${ }^{11}$ However, results from human trials comparing RCP with DHCA have not shown a similar benefit. Data from a single institution randomized trial that we conducted demonstrated no clear difference between RCP and DHCA on developmental status 1 year after Norwood surgery using the Bayley Scales of Infant Developmental. ${ }^{12}$ Similarly, 2 additional studies using historical or nonrandomized contemporary controls also failed to demonstrate a benefit in developmental testing or magnetic resonance imaging-detected brain injury when RCP was compared with DHCA. ${ }^{13,14}$

In addition to RCP, another technique that has been described for use in aortic arch repair is intermittent perfusion (IP). This procedure, which involves brief periods of cerebral perfusion during DHCA, has been shown to ameliorate the negative metabolic and ultrastructural effects of DHCA in a porcine model, but again, no empirical evidence exists to support such a benefit in humans. ${ }^{15}$ Although the use of IP seems to be limited, anecdotal reports in the literature suggest that RCP is now used widely among cardiothoracic surgeons who perform aortic arch reconstruction. Yet, despite the uncertainty over the optimal perfusion technique for neonatal aortic arch repair, true evidence of the equipoise necessary to support a randomized clinical trial is lacking. Because of the lack of published data on the prevalence of RCP and IP use in contrast with DHCA and on the underlying reasons for choosing these newer adjuvant procedures over DHCA, we conducted a survey among congenital heart surgeons who perform neonatal arch reconstruction to evaluate the rates of use of these techniques and to determine the reasons that underlie that treatment decision.

\section{PERFUSION TECHNIQUES IN NEONATAL ARCH RECONSTRUCTION: A SURVEY OF PREFERENCES AND ATTITUDES}

Congenital heart surgeons of North America were surveyed on the use of a variety of perfusion techniques during aortic arch reconstruction operations. Additional questions were aimed at determining the level of evidence-based medicine that was available to support their choice. Approval for the study was granted by the University of Michigan Medical School Institutional Review Board. The Society of Thoracic Surgeons' Congenital Heart Surgeons Workforce Database was queried for all cardiac surgeons within North America who perform congenital heart operations. This list of surgeons was cross-referenced to the United States and Canada Pediatric Cardiologists, Congenital Heart Surgeons, and 


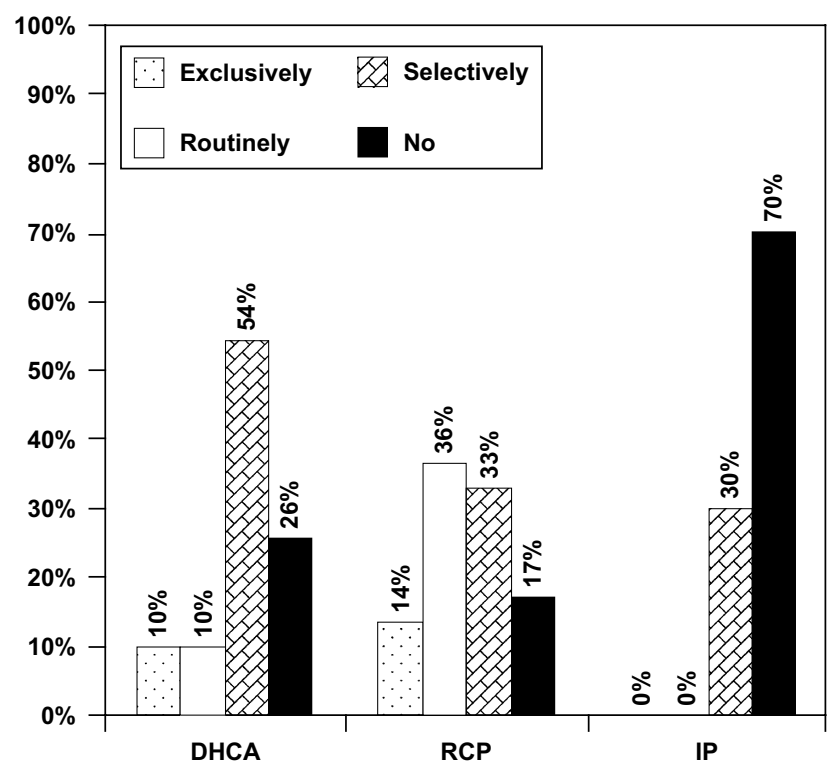

FIGURE 1. Proportion of surgeons using each perfusion type. DCHA, Deep hypothermic circulatory arrest; $R C P$, regional cerebral perfusion; $I P$, intermittent perfusion.

Hospitals Providing Open Heart Surgery for Children Directory-August 2006 from the American Academy of Pediatrics. A survey was developed to measure the frequency of various perfusion techniques and to assess the reasoning behind the choices made. Requests to participate were sent via e-mail, and the Internet-based survey was conducted using Websurveyer (www.websurveyer.com). After an initial question confirming that the surgeon did perform neonatal aortic arch reconstruction, they were asked to complete the brief survey. The respondents were queried on whether they used DHCA, RCP, or IP for neonatal arch repair exclusively, routinely, selectively, or not at all. The definition of each procedure, respectively, was provided in the instructions that preceded each question item. Respondents were then asked the basis for their decision on the choice of technique. The decision response items were designed to approximate the standard levels of evidence-based support: (1) definitive literature, (2) suggestive literature, (3) opinions of experts, (4) personal experience, (5) no alternative, and (6) other (with text field for description). Respondents who reported using any of the techniques either routinely or selectively were then queried about the factors that influenced their decision to use a method for a particular case. Response items were (1) length of procedure, (2) type of procedure, (3) patient anatomy, (4) patient weight, (5) patient age, and (6) other (with a text field for description). More than 1 response choice was allowed for this latter question.

\section{SURVEY RESULTS}

From the roster of 251 surgeons identified as potentially eligible to participate, not including the 15 surgeons for
TABLE 1. Reasons for using a technique exclusively or routinely

\begin{tabular}{lrrrrrr}
\hline & \multicolumn{2}{c}{ DHCA $(\mathbf{n}=\mathbf{2 8})$} & & \multicolumn{2}{c}{$\mathbf{R C P}(\mathbf{n}=\mathbf{7 0})$} \\
\cline { 2 - 3 } \cline { 5 - 6 } & $\mathbf{n}$ & $\mathbf{0}$ & & $\mathbf{n}$ & $\%$ \\
\hline Definitive literature & 5 & $17.9 \%$ & & 4 & $5.7 \%$ \\
Suggestive literature & 11 & $39.3 \%$ & & 50 & $71.4 \%$ \\
Opinions of experts & 16 & $57.1 \%$ & & 32 & $45.7 \%$ \\
Personal experience & 21 & $75.0 \%$ & & 45 & $64.3 \%$ \\
No alternative & 14 & $50.0 \%$ & & 9 & $12.9 \%$ \\
Other & 1 & $3.6 \%$ & & 7 & $10.0 \%$ \\
\hline$D C H A$, Deep hypothermic circulatory arrest; $R C P$, regional cerebral perfusion. Re- \\
spondents could select all that applied (eg, rows are not mutually exclusive).
\end{tabular}

whom we were unable to find a valid e-mail address, we successfully recruited 140 of $212(66 \%)$.

\section{RATES OF USE}

The relative proportion of use by perfusion technique is shown in Figure 1. Twenty percent of respondents reported routine or exclusive use of DHCA during aortic arch repair, compared with $50 \%$ of respondents who reported routine or exclusive use of RCP. In contrast, none of the responding surgeons reported IP use on a routine or exclusive basis. In fact, $70 \%$ of respondents reported not using IP at all, compared with $26 \%$ and $17 \%$ not using DHCA or RCP, respectively.

\section{SUPPORT FOR USING A TECHNIQUE}

Table 1 shows the percentages by response category for why surgeons choose DHCA or RCP either exclusively or routinely (combined). Although RCP was more frequently used regularly than DHCA, the proportion who reported a definitive literature supporting its use was considerably lower for RCP $(5.7 \%)$ than for DHCA $(17.9 \%)$. The 2 response items most frequently endorsed for RCP was suggestive literature $(71.4 \%)$ and personal experience $(64.3 \%)$. For DHCA, the 2 most frequent endorsements were personal experience $(75 \%)$ and opinions of experts $(57 \%)$. Results were similar for those reporting using DHCA or RCP selectively (Table 2). For those answering "not at all," the reasons for not using DHCA, RCP, or IP are shown in Table 3.

\section{FACTORS INFLUENCING THE DECISION TO USE A TECHNIQUE}

For respondents who reported using more than 1 technique (ie, answered either "routinely" or "selectively"), the relative distribution of decision factors endorsed to apply a particular perfusion method is shown in Table 4. The factors influencing choice of procedure were similar for DHCA and RCP, with the length of procedure, type of procedure, and patient anatomy being most frequently cited. Length of procedure and patient age were more frequently identified as factors influencing use of IP than either DHCA or RCP. 
TABLE 2. Reasons for using a technique selectively

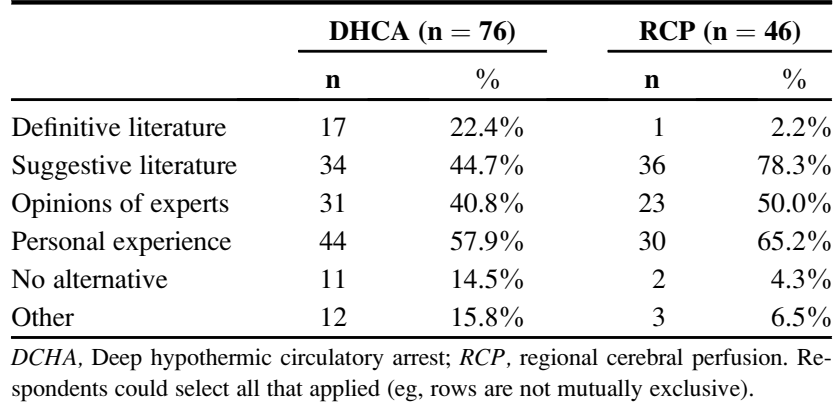

\section{INFERENCES REGARDING THE RATES OF USE AND SUPPORT FOR USING A TECHNIQUE}

The results of this survey demonstrate the current rates of use of the 3 perfusion techniques available for neonatal aortic arch reconstruction. There is clearly appropriate concern regarding the safety of DHCA, with $80 \%$ of respondents only using DHCA selectively or avoiding it all together. This concern would seem warranted by the relatively large body of literature implicating DHCA in poor neurodevelopmental outcomes in both human and animal studies. ${ }^{5-7,9}$ In response, half of the surgeons performing neonatal arch reconstructions endorsed $\mathrm{RCP}$ as their perfusion technique of choice.

\section{RATES OF USE}

There are several interesting observations that can be made from the data from this survey study. First, a greater percentage of surgeons apparently believe that DHCA is inherently worse than RCP. The results demonstrated that $54 \%$ of respondents use DHCA only selectively and $26 \%$ not at all, compared with $33 \%$ and $17 \%$, respectively, for RCP. These data suggest that a greater number of surgeons think that DHCA is to be avoided when possible or not used at all in favor of RCP. In addition, this survey demonstrates that the use of RCP is widespread. Twenty percent of respondents use DHCA either exclusively or routinely, whereas $50 \%$ use RCP exclusively or routinely, suggesting they believe that their method of choice represents "best practice", or "standard of care."

\section{SUPPORT FOR USING A TECHNIQUE}

For those respondents answering "exclusively" or "routinely," the most common reason cited for using DHCA was " "personal experience," followed by "expert opinion.', For $\mathrm{RCP}$, the most common reason for using the technique exclusively or routinely was a "suggestive literature," followed by "personal experience."

Similarly, for surgeons using RCP or DHCA selectively, the most common reason cited by respondents for the use of DHCA was "personal experience", and for the use of RCP was "suggestive literature." These data would appear para-
TABLE 3. Reasons for not using a technique

\begin{tabular}{|c|c|c|c|c|c|c|}
\hline & \multicolumn{2}{|c|}{ DHCA $(n=36)$} & \multicolumn{2}{|c|}{$\operatorname{RCP}(n=24)$} & \multicolumn{2}{|c|}{ IP $(\mathbf{n}=98)$} \\
\hline & $\mathbf{n}$ & $\%$ & $\mathbf{n}$ & $\%$ & $\mathbf{n}$ & $\%$ \\
\hline Definitive literature & 1 & $2.8 \%$ & 1 & $4.2 \%$ & 2 & $2.0 \%$ \\
\hline Suggestive literature & 25 & $69.4 \%$ & 17 & $70.8 \%$ & 21 & $21.4 \%$ \\
\hline Opinions of experts & 11 & $30.6 \%$ & 5 & $20.8 \%$ & 15 & $15.3 \%$ \\
\hline Personal experience & 12 & $33.3 \%$ & 12 & $50.0 \%$ & 64 & $65.3 \%$ \\
\hline Other & 5 & $13.9 \%$ & 1 & $4.2 \%$ & 14 & $14.3 \%$ \\
\hline
\end{tabular}

$D C H A$, Deep hypothermic circulatory arrest; $R C P$, regional cerebral perfusion; $I P$, in termittent perfusion. Respondents could select all that applied (eg, rows are not mutually exclusive).

doxical, because the body of literature is larger for DHCA than for RCP. However, this finding could be explained by the fact that DHCA is a more long-standing technique, with which most congenital surgeons have extensive familiarity and are therefore comfortable with their personal experience. With RCP being in use for a shorter period of time than DHCA, there is less personal experience, and thus surgeons may prefer to look to the literature to support their decision.

For those surgeons responding that they did not use a particular technique at all, the most common reason given for both DHCA and RCP was "suggestive literature." For IP, the most common reason given was "personal experience." These citations of "suggestive literature" for DHCA and RCP would seem expected because there are numerous studies, including the Boston Circulatory Arrest Trial, outlining the risks associated with $\mathrm{DHCA},{ }^{5-7,9}$ as well as the aforementioned studies failing to show a benefit of RCP compared with DHCA. ${ }^{12-14}$ In regard to IP, with the exception of the single animal study by Langley and associates, ${ }^{15}$ there is no other literature available to our knowledge, perhaps explaining why most commonly "personal experience" (or lack thereof) was cited as the reason for avoiding the technique.

\section{INFERENCES REGARDING THE ROLE OF} EVIDENCE-BASED MEDICINE IN OUR PRACTICE

From these data, one may also make inferences regarding the current role of evidence-based medicine in clinical

TABLE 4. Factors influencing the decision to select a particular technique

\begin{tabular}{|c|c|c|c|c|c|c|}
\hline & \multicolumn{2}{|c|}{ DHCA $(n=90)$} & \multicolumn{2}{|c|}{$\mathbf{R C P}(\mathbf{n}=97)$} & \multicolumn{2}{|c|}{ IP $(n=42)$} \\
\hline & $\mathbf{n}$ & $\%$ & $\mathbf{n}$ & $\%$ & $\mathbf{n}$ & $\%$ \\
\hline Length of procedure & 63 & $70.0 \%$ & 75 & $77.3 \%$ & 41 & $97.6 \%$ \\
\hline Type of procedure & 78 & $86.7 \%$ & 82 & $84.5 \%$ & 37 & $88.1 \%$ \\
\hline Patient anatomy & 81 & $90.0 \%$ & 86 & $88.7 \%$ & 34 & $81.0 \%$ \\
\hline Patient weight & 46 & $51.1 \%$ & 44 & $45.4 \%$ & 18 & $42.9 \%$ \\
\hline Patient age & 31 & $34.4 \%$ & 34 & $35.1 \%$ & 20 & $47.6 \%$ \\
\hline Other & 8 & $8.9 \%$ & 3 & $3.1 \%$ & 0 & - \\
\hline
\end{tabular}

$D C H A$, Deep hypothermic circulatory arrest; $R C P$, regional cerebral perfusion; $I P$, in termittent perfusion. Respondents could select all that applied (eg, rows are not mutually exclusive). 
decision making. At least as pertains to choosing the optimal perfusion techniques for neonatal arch reconstruction, the surgeons responding to the survey were willing to accept a rather low level of evidence-based medicine to adopt a new technique. There also seems to be a rather low bar for surgeons to define literature as "supportive" or "definitive." Whether citing the reasons for choosing DHCA (57\% "suggestive" or "definitive" literature) or RCP (77\% "suggestive" or "definitive" literature), we as surgeons believe there is strong support for what we do, even though a review of the literature comparing the 2 techniques does not bear out this belief. There is only 1 randomized controlled trial, and this study did not demonstrate a difference in developmental testing between RCP and DHCA. ${ }^{12}$ The remaining 2 comparative studies ${ }^{13,14}$ and the numerous case series are not of sufficient methodologic quality to define the role of RCP based on the Jadad quality assessment scale ${ }^{16}$ or standard levels of evidence-based medicine. Furthermore, recent literature on neurocognitive outcomes in patients undergoing congenital heart surgery would suggest that genetic polymorphisms and hematocrit levels on cardiopulmonary bypass may have a greater impact than duration of DHCA. ${ }^{17-19}$ Thus, it is unknown whether the trend for using RCP is beneficial, detrimental, or of no added consequence to the patient.

\section{CONCLUSIONS}

On the basis of the results of this survey, as well as a review of the literature, it is clear that the optimal perfusion method for aortic arch reconstruction remains unknown and that equipoise exists among surgeons caring for neonates requiring aortic arch reconstruction. The need to improve our understanding of and to base clinical management decisions on solid evidence-based medicine is obvious. The impetus for a multi-institutional randomized clinical trial comparing DHCA and RCP would seem equally as clear.

\section{References}

1. Mahle WT, Spray TL, Wernovsky G, Gaynor JW, Clark BJ 3rd. . Survival after reconstructive surgery for hypoplastic left heart syndrome: a 15 year experience from a single institution. Circulation. 2000;102(19 suppl. 3):III136-41.

2. Bove EL, Lloyd TR. Staged reconstruction for hypoplastic left heart syndrome. Contemporary results. Ann Surg. 1996;224:387-94.

3. Tweddell JS, Hoffman GM, Mussatto KA, Fedderly RT, Berger S, Jaquiss RD, et al. Improved survival of patients undergoing palliation of hypoplastic left heart syndrome: lessons learned from 115 consecutive patients. Circulation. 2002; 106(suppl I):I82-9.

4. Kern JH, Hayes JH, Michler RE, Gersony WM, Quagebeur JM. Survival and risk factor analysis for the Norwood procedure for hypoplastic left heart syndrome. Am J Cardiol. 1997;80:170-4.

5. Oates RK, Simpson JM, Turnbull JAB, Cartmill TB. The relationship between intelligence and duration of circulatory arrest with deep hypothermia. J Thorac Cardiovasc Surg. 1995;110:786-92.

6. Newburger JW, Jonas RA, Wernovsky G, Wypij D, Hickey PR, Kuban KC, et al. A comparison of perioperative neurologic effects of hypothermic circulatory arrest versus low flow cardiopulmonary bypass in infant heart surgery. $N$ Engl J Med. 1993;329:1057-64.

7. Bellinger DC, Wypij D, Kuban KC, Rappaport LA, Hickey PR, Wernovsky G, et al. Developmental and neurological status of children at 4 years of age after heart surgery with hypothermic circulatory arrest or low-flow cardiopulmonary bypass. Circulation. 1999;100:526-32.

8. Asou T, Kado H, Imoto Y, Shiokawa Y, Tominaga R, Kawachi Y, et al. Selective cerebral perfusion technique during aortic arch repair in neonates. Ann Thorac Surg. 1996;61:1546-8.

9. Pigula FA, Nemoto EM, Griffith BP, Siewers RD. Regional low-flow perfusion provides cerebral circulatory support during neonatal aortic arch reconstruction. J Thorac Cardiovasc Surg. 2000;119:331-9.

10. Tchervenkov CI, Chu VF, Shum-Tim D, Laliberte E, Reyes TU. Norwood operation without circulatory arrest: a new surgical technique. Ann Thorac Surg. 2000; 70:1730-3.

11. Myung RJ, Petko M, Judkins AR, Schears G, Ittenbach RF, Waibel RJ, et al. Regional low-flow perfusion improves neurologic outcome compared with deep hypothermic circulatory arrest in neonatal piglets. J Thorac Cardiovasc Surg. 2004; 127:1051-7.

12. Goldberg CS, Bove EL, Devaney EJ, Mollen E, Schwartz E, Tindall S, et al. A randomized clinical trial of regional cerebral perfusion versus deep hypothermic circulatory arrest: outcomes for infants with functional single ventricle. J Thorac Cardiovasc Surg. 2007; 133:880-7.

13. Dent CL, Spaeth JP, Jones BV, Schwartz SM, Glauser TA, Hallinan B, et al. Brain magnetic resonance imaging abnormalities after the Norwood procedure using regional cerebral perfusion. J Thorac Cardiovasc Surg. 2006; 131:190-7.

14. Visconti KJ, Rimmer D, Gauvreau K, del Nido P, Mayer JE, Hagino I, et al. Regional low-flow perfusion versus circulatory arrest in neonates: one-year neurodevelopmental outcome. Ann Thorac Surg. 2006;82:2207-13.

15. Langley SM, Chai PJ, Miller SE, Mault JR, Jaggers JJ, Tsui SS, et al. Intermittent perfusion protects the brain during deep hypothermic circulatory arrest. Ann Thorac Surg. 1999;68:4-12.

16. Jadad AR, Moore RA, Carroll D. Assessing the quality of randomized controlled clincal trials: is blinding necessary? Control Clin Trials. 1996;17:1-12.

17. Gaynor JW, Wernovsky G, Jarvik GP, Bernbaum J, Gerdes M, Zackai E, et al. Patient characteristics are important determinants of neurodevelopmental outcome at one year of age after neonatal and infant cardiac surgery. $J$ Thorac Cardiovasc Surg. 2007;133:1344-53.

18. Jonas RA, Wypij D, Roth SJ, Bellinger DC, Visconti KJ, du Plessis AJ, et al. The influence of hemodilution on outcome after hypothermic cardiopulmonary bypass: results of a randomized trial in infants. J Thorac Cardiovasc Surg. 2003; 126:1765-74.

19. Wypij D, Jonas RA, Bellinger DC, Del Nido PJ, Mayer JE, Bacha EA, et al. The effect of hematocrit during hypothermic cardiopulmonary bypass in infant heart surgery: results from the combined Boston hematocrit trials. J Thorac Cardiovasc Surg. 2008;135:355-60. 